\title{
The Effects of Family Structure on the Development of Bilinguality
}

\author{
Lily Halsted \\ Queens University of Charlotte, Charlotte, USA \\ Email: halstedl@queens.edu
}

Received June $14^{\text {th }}, 2013$; revised July $17^{\text {th }}, 2013$; accepted August $12^{\text {th }}, 2013$

\begin{abstract}
Copyright (c) 2013 Lily Halsted. This is an open access article distributed under the Creative Commons Attribution License, which permits unrestricted use, distribution, and reproduction in any medium, provided the original work is properly cited.
\end{abstract}

\begin{abstract}
This study examines the role of family structure in the development of different levels of bilinguality. Students from five different public and private universities responded to an extensive survey on various aspects of bilinguality. Participants were divided into three groups: monolinguals, non-fluent bilinguals and fluent bilinguals. In line with the initial hypothesis, higher levels of bilinguality correlated with having more bilingual family members. Also further evidence was found for the importance of the mother, father and sisters in becoming bilingual. Additionally, the presence of bilingual step-parents and grandparents on acquisition and maintenance of a second language was examined and fund to be much less influential than the role of the parents. Finally, the influence of socio-economic status (SES) on development of bilinguality was measured with no clear effect being found. The unique contribution of this study is that it attempts to connect the influence of specific family members to different levels of bilinguality.
\end{abstract}

Keywords: Bilingualism; Heritage Languages; Monolinguals; Language Use Surveys

\section{Introduction}

It is estimated that over $70 \%$ of the world's population speak more than one language (Trask, 1999). Trask asserts that being able to speak two or more languages has most likely been the norm across societies for thousands of years. A key question is how large majorities of people - then and now - have been able to acquire and maintain more than a single language. One possible explanation is the influence of family members and the home linguistic environment on the individual. In recent years there have been a number of studies that have examined the effect of family dynamics on the presence and advancement of bilinguality in children (Harding \& Riley, 1986; Gregory \& Williams, 2000; Kenner, 2000; Obied, 2009; Dale, Harlaar, Haworth, \& Plomin, 2010). In the United States immigrants create the most common bilingual environments in families. We know that immigrant children often choose not to interact with one another in their parents' (heritage) language but instead adopt the dominant language of that society (Miller, 1983). This choice can ultimately lead to the inhibition of the parents' language in the younger generation (Levy, McVeigh, Marful, \& Anderson, 2007). This may be why the rate of bilinguality is estimated to be only $20 \%$ in the United States (Shin \& Kominski, 2010) as opposed to $70 \%$ for the rest of the world.

There have been many studies that have documented some of the benefits of bilinguality in such areas as executive control (Bialystok, 1986, 1988, 1999; Bialystok \& Craik, 2010), achievements in physics and mathematics (Farrell, 2011), success in acquisition of foreign languages as adults (Eisenstein, 1980; Thomas, 1988; Keshavarz \& Astaneh, 2004) and a decreased reduction in attentional processes as a result of natural aging for bilinguals (Bialystok, Craik, Klein, \& Viswanathan, 2004; Bia- lystok, Craik, \& Ryan, 2006). At the same time, there seem to be some disadvantages to being bilingual including lower scores recorded in vocabulary tests in both languages (Oller \& Eilers, 2002) and a reduction of access to the first language after a period of immersion in the second language (Linck, Kroll \& Sunderman, 2009). As the lifelong advantages of being bilingual would seem to outweigh the disadvantages it is important to determine how one becomes and remains bilingual or even multilingual.

In general, the path of bilingual child rearing seems to be influenced by family structure. Within the immediate family, the role of mothers in the encouragement and promotion of bilingualism in children has been emphasized in the past (Baker, 2000). The argument is that mothers, especially stay at home mothers, spend more time with their children. If the mothers speak a different language, they have more opportunities to promote bilinguality in their children. Of course this will only occur if the mother chooses to use her native language with her children. Some mothers prefer to promote the dominate language of their culture with their children to make sure the child assimilates better into society.

The role of the father in the linguistic development of children, on the other hand, is more reflective of the affiliative nature of his relationship with his smaller children. Fathers' language use often relates to the same context as their children, in contrast to the mother's language which tends to be more practical and disciplinary in nature (Baker, 2000). However, when the mother is the speaker of the minority language in the family the children seem to have a higher chance of adoption of that language compared to when the father is the minority speaker. This effect exists, perhaps, because even in our mod- 
ern societies mothers spend more time with their children (Clyne, 1982; Kamada, 1995).

Furthermore, some studies show that the possibility of bilingual development increases when both parents speak the minority language at home or when they both speak the minority language but only one also speaks the dominant language (Yamamoto, 2001). Clearly, this is a fairly stringent requirement for the adoption of a minority language. In addition, some of the newer studies place greater emphasis on the importance of schooling in the promotion and maintenance of bilinguality (Shin, 2005).

In terms of the possible influence of siblings in the bilingual development of the child, some studies indicate that first-born children are more likely to become bilinguals in comparison to later born children (Manaster, Rhodes, Marcus, \& Chen, 1998). It also seems that older children are more likely to become bilingual and encourage and promote bilinguality and biliteracy in their younger siblings (Baker, 1995; Gregory \& Williams, 2000, Obied, 2009). As for a particular dynamic among siblings, there is some evidence that in general sisters are better at encouraging the advancement of the minority language in their siblings and can be good language teachers to their younger brothers (Azimita \& Hesser, 1993; Rashid \& Gregory, 1997).

Most studies that focus on family dynamics and second language development tend to examine the evidence within one culture or one linguistic environment (Obied, 2009, Portuguese; Yamamoto, 2001, Japanese; Shin, 2005, Korean; Rashid \& Gregory, 1997, Sylheti; Farrell, 2011, Maltese; Bialystok, Craik, Klein, \& Viswanathan, 2004, Tamil; Linck, Kroll, \& Sunderman, 2009, Spanish). We know that different cultural attitudes, as well as pride and the degree of determination to preserve one's heritage and language, can influence how much of an effort parents and the family as a whole make to preserve their native language (Baker, 1995). Now, as has been true many other times during the course of human history, all languages are not viewed as equal. Based on the large number of people who wish to adopt or communicate in a particular language, some languages, such as Latin, were considered prestige languages. Currently, in many areas of the world English is considered a prestige language. This is in contrast to heritage languages which are spoken by fewer individuals in the community and are typically not taught in schools. Over time, these heritage languages tend to lose ground to prestige languages and are increasingly forgotten by later generations of immigrant families (Lambert \& Taylor, 1990; Shum, 2001).

In an effort to control for possible differences in culture, ethnicity and language as they relate to family structure, the subjects in the present study were recruited from five different colleges and universities in two different states. By casting a wide net it was possible to include participants who spoke a diverse range of heritage languages and came from families with origins in many different countries outside of the United States. Socioeconomic status (SES) has also been considered as another factor that can affect bilinguality in children (Morton \& Harper, 2007). To see if SES had any role, the subjects for the current study were recruited from a variety of academic institutions (private and state universities, and a community college) with very different tuition and family income levels. Overall, the advantages of being bilingual outweigh the disadvantages. Clearly, many societies in the world are aware of this fact and adhere to it, while in the United States we continue to lag behind the rest of the world in the development and maintenance of bilinguality in our children and adolescents.

In the present study it was hypothesized that with bilingual participants, and especially fluent bilinguals, there would be a strong influence of immediate family members (parents and siblings) on the advancement of the subjects' second language fluency. This will not be the case in monolinguals and will play a less significant role with less fluent bilinguals. It was expected that grandparents would not have as much influence as parents or siblings as they tend to be less available during a person's childhood when most language development takes place. In general, it was expected that bilingual and fluent bilingual subjects have more family members in their household who speak a minority language. It was also expected that step-parents would play a similar role as grandparents in a child's second language development. School was expected to have a lesser influence than family on second language acquisition.

\section{Method}

\section{Subjects}

The subjects for this study consisted of 122 college students, 93 of these students $(76 \%)$ were females and $29(24 \%)$ were males. This ratio reflects the larger number of female psychology students at the participating institutions. The subjects for this study included students from four public and private universities as well as a community college. Four of these institutions were located in North Carolina and one in Tennessee.

Participants ranged in age from 18 to 52 years old. The mean was 22.4 years $(\mathrm{SD}=5.71)$ and median was 21 years. Out of 122 subjects, 49 reported themselves to be bilingual. The remaining 73 subjects spoke only one language: (monolingual). All subjects were English speakers, with the second language spoken by the bilingual subjects included Spanish, French, Polish, Farsi and German. Most of the subjects were enrolled in various psychology classes and participated in this study in exchange for extra credit. The socio-economic background of subjects was diverse. A high proportion of the private university students came from higher income families, while the students from the public universities were more representative of the middle class. Students attending the community college had a lower average family income compared to the other two groups. Specific characteristics of the subjects are reported in Table 1.

\section{Procedures and Measures}

A 100-item, multi-scale online survey on bilinguality was designed for this study and made available to participating students. In addition to basic demographic information, the survey measured the level of competence of the participants in a second language (reading, writing and speaking). It also measured the subject's level of interest and engagement in their second language, as well as the amount of time spent in reading or conversation in that language. The 48 questions that dealt specifically with the levels, depth and the frequency of bilingual behaviors in the subjects are listed in the appendix.

In this survey we also tried to determine the sources and causes of bilinguality as it is influenced by family structure. Toward the end of the survey there were several questions asking about second language abilities for each member of a par- 
Table 1.

Characteristics of the participant groups.

\begin{tabular}{|c|c|c|c|}
\hline Characteristic & Monolinguals & $\begin{array}{l}\text { Non-fluent } \\
\text { bilinguals }\end{array}$ & $\begin{array}{c}\text { Fluent } \\
\text { bilinguals }\end{array}$ \\
\hline Number of participants & 73 & 25 & 24 \\
\hline Mean age (years) & 22.8 & 20.9 & 22.9 \\
\hline $\begin{array}{l}\text { Mean age of second } \\
\text { language acquisition (years) }\end{array}$ & $\mathrm{n} / \mathrm{a}$ & 10.5 & 3.3 \\
\hline $\begin{array}{l}\% \text { born in US (or in } \\
\text { English-speaking countries) }\end{array}$ & $100 \%$ & $88 \%$ & $50 \%$ \\
\hline$\%$ with mother born outside US ${ }^{\mathrm{a}}$ & $1 \%$ & $20 \%$ & $83 \%$ \\
\hline$\%$ with father born outside $U^{\mathrm{a}}$ & $4 \%$ & $12 \%$ & $87 \%$ \\
\hline $\begin{array}{l}\% \text { learning second language } \\
\text { before age } 5\end{array}$ & $\mathrm{n} / \mathrm{a}$ & $28 \%$ & $75 \%$ \\
\hline $\begin{array}{l}\% \text { attending foreign language } \\
\text { classes (after school/weekends) }\end{array}$ & $1 \%$ & $4 \%$ & $21 \%$ \\
\hline
\end{tabular}

ticipant's immediate (mother, father, step parents or siblings) and extended (grandparents) family. There were also questions about each parent's place (country) of birth, level of education, linguistic competence and how often they speak a second language at home.

\section{Results}

\section{Monolingual versus Bilingual}

The first analysis for this study was to determine the level of bilingual capabilities of the respondents. In the present study subjects were considered to be bilingual if they 1) said they spoke a second language, 2) claimed to still speak the language, and 3) could speak the language at least "pretty well." These questions were followed by more in-depth question about their linguistic abilities.

Nearly half (45\%) of the respondents answered "yes" to the two questions "Do you speak any languages other than English? and "Do you still speak this 'second' language?" After excludeing six subjects who responded "not very well" to a later question on language fluency ("How well can you speak your second language?"), there were a total of 49 respondents (40\%) considered to be bilingual for this study. An additional 73 respondents were classified as monolinguals. Among the bilingual subjects, 24 reported being fluent in their second language while the other 25 felt they could speak their second language either "pretty well" or "very well."

\section{Demographic Characteristics}

There were no significant associations between bilinguality and gender $\left(\chi^{2}(1)=0.28, \mathrm{~ns}\right)$, age $(\mathrm{F}(1,119)=0.72, \mathrm{~ns})$, year in school $\left(\chi^{2}(3)=4.85\right.$, ns), or family income $\left(\chi^{2}(1)=0.02\right.$, ns). Similarly, among bilinguals there were no significant associations between language fluency and gender $\left(\chi^{2}(1)=0.725, \mathrm{~ns}\right)$, age $(\mathrm{F}(1,48)=2.56, \mathrm{~ns})$ or year in school $\left(\chi^{2}(3)=4.64\right.$, ns $)$. However, within the sample of bilinguals there was a significant association with family income $\left(\chi^{2}(1)=5.03, p<0.03\right)$, with fluent bilinguals more likely to come from homes with a family income under $\$ 100,000$.

\section{Presence of Bilingual Family Members}

\section{Monolinguals versus Bilinguals}

Table 2 presents the percentages of monolingual and bilingual respondents with specific family members who spoke a second language. All survey respondents were asked the question "Growing up, were there other family members who lived in your home who regularly spoke a language other than English" and if so, "what is their relationship to you?" Among monolinguals it was rare to find any other family members who spoke a second language. The highest percentages were for mother $(6 \%)$, father $(6 \%)$ and grandmother $(6 \%)$. In this group only $4 \%$ reported having both a mother and a father who spoke a second language.

In contrast, $61 \%$ of the bilingual group reported one or more family members who spoke another language. The highest percentages with this group were for mother (49\%) and father (47\%). For $42 \%$ of bilinguals, both parents spoke a second language. Counting up the total number of family members who spoke a second language, the mean for bilinguals $(2.41, \mathrm{SE}$ $=0.38)$ was significantly greater than the mean for monolinguals $(0.23, \mathrm{SE}=0.08), \mathrm{F}(1,120)=43.94, p<0.001$.

Table 3 presents the zero-order correlations of presence/absence of each type of bilingual family member with whether a subject was monolingual or bilingual. The correlations were significant for every family member with the exception of step-mother. A stepwise linear regression was then performed to determine more precisely which specific bilingual family members had the strongest association with the subjects' bilinguality. The strongest predictors of bilingualism were having a bilingual mother $(\beta=0.32, \mathrm{SE}=0.13, p<0.01)$ followed by having a bilingual sister $(\beta=0.26, \mathrm{SE}=0.16, p<0.05)$. The overall model fit was $\mathrm{R}^{2}=0.29$.

\section{Fluent versus Non-Fluent Bilinguals}

As shown in Table 1, half of the fluent bilinguals in this

Table 2.

Percent of family members who spoke a language other than English: monolinguals and bilinguals.

\begin{tabular}{ccc}
\hline Family & Monolingual & Bilingual \\
\hline Member & $(\mathrm{N}=73)$ & $(\mathrm{N}=49)$ \\
Mother & $6 \%$ & $49 \%$ \\
Father & $6 \%$ & $47 \%$ \\
Step-mother & $1 \%$ & $6 \%$ \\
Step-father & $1 \%$ & $8 \%$ \\
Grandmother & $4 \%$ & $29 \%$ \\
Grandfather & $4 \%$ & $37 \%$ \\
Sister & $4 \%$ & $35 \%$ \\
Brother & $0 \%$ & $31 \%$ \\
Any member & $11 \%$ & $61 \%$ \\
\hline
\end{tabular}


Table 3.

Correlation of presence of bilingual family member with subjects' bilinguality and level of fluency.

\begin{tabular}{ccccc}
\hline Family & \multicolumn{2}{c}{ Bilinguality } & \multicolumn{2}{c}{ Fluency } \\
\hline Member & \multicolumn{2}{c}{$(\mathrm{N}=122)$} & \multicolumn{2}{c}{$(\mathrm{N}=49)$} \\
& $\mathrm{r}$ & $p^{\mathrm{a}}$ & $\mathrm{r}$ & $p^{\mathrm{a}}$ \\
Mother & 0.51 & 0.001 & 0.67 & 0.001 \\
Father & 0.49 & 0.001 & 0.72 & 0.001 \\
Step-mother & 0.13 & 0.080 & 0.26 & 0.036 \\
Step-father & 0.17 & 0.003 & 0.16 & 0.136 \\
Grandmother & 0.40 & 0.001 & 0.35 & 0.007 \\
Grandfather & 0.35 & 0.001 & 0.37 & 0.004 \\
Sister & 0.49 & 0.001 & 0.57 & 0.001 \\
Brother & 0.46 & 0.001 & 0.50 & 0.001 \\
\hline
\end{tabular}

Note: ane-tailed.

study were born outside of the United States in non-English speaking countries. In contrast, only $12 \%$ of the non-fluent bilinguals were born outside the US. Furthermore, fully $75 \%$ of the fluent bilinguals started learning their heritage language before the age of five, compared to only $28 \%$ of the non-fluent bilinguals. In addition, within the bilingual group, a large majority of the fluent speakers had family members who spoke another language at home. Table 4 (and Figure 1) shows that the highest percentages were for mother $(83 \%)$, father $(83 \%)$ and sister $(63 \%)$. In this group of fluent bilinguals, $79 \%$ reported having both a mother and father who spoke a second language. For the bilinguals who were less fluent in the second language, only about one in six had another family member who spoke another language: mother $(16 \%)$, father $(12 \%)$, and grandmother $(20 \%)$. Only $8 \%$ of the non-fluent bilinguals had both a mother and father who spoke a second language. Counting up the total number of family members who spoke a second language, the mean for fluent bilinguals $(4.08, \mathrm{SD}=0.51)$ was significantly greater than the mean for non-fluent bilinguals $(0.80, \mathrm{SD}=0.33), \mathrm{F}(1,120)=43.94, p<0.0001$.

As presented in Table 3, even within the two groups of bilinguals, presence/absence of each type of bilingual family member was still correlated significantly with whether a subject was a fluent or non-fluent bilingual speaker. Within the two groups of bilingual respondents, a stepwise linear regression found that the presence of a bilingual father was the best predictor of overall second language fluency $(\beta=0.72, \mathrm{SE}=0.10$, $p<.0001)$. The overall model fit was $\mathrm{R}^{2}=0.51$.

\section{Where Was the Second Language Learned?}

Another question asked only of the bilinguals was "where did you learn to speak this second language?" Table 5 (and Figure 2) presents the percentage response for specific sources of language learning for the two levels of bilinguality. For non-fluent bilinguals the primary source of language learning was "at school" (80\%). In contrast, for the fluent bilinguals, parents edged out school by $79 \%$ to $67 \%$. Table 5 also presents the zero-order correlations for each source of learning with degree of bilinguality. Learning from parents, grandparents and

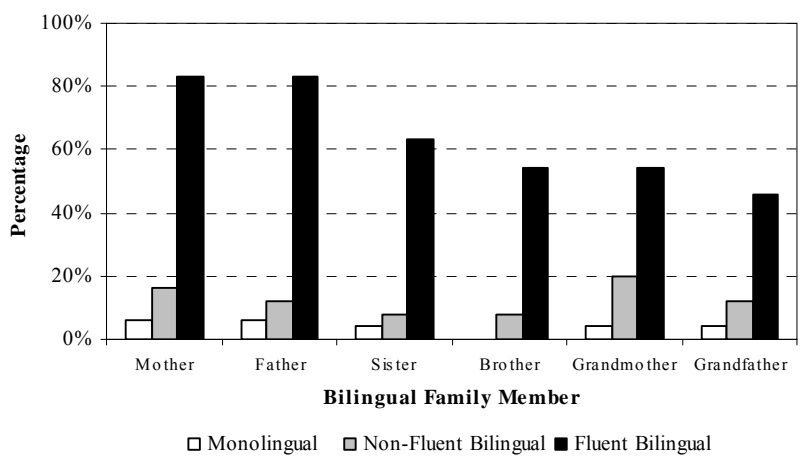

Figure 1.

Fluency level related to presence of bilingual family members.

Table 4.

Percent of family members who spoke a language other than English: non-fluent bilinguals and fluent bilinguals.

\begin{tabular}{ccc}
\hline Family & Non-fluent bilingual & Fluent bilingual \\
\hline Member & $(\mathrm{N}=25)$ & $(\mathrm{N}=24)$ \\
Mother & $16 \%$ & $83 \%$ \\
Father & $12 \%$ & $83 \%$ \\
Step-mother & $0 \%$ & $13 \%$ \\
Step-father & $4 \%$ & $13 \%$ \\
Grandmother & $20 \%$ & $54 \%$ \\
Grandfather & $12 \%$ & $46 \%$ \\
Sister & $8 \%$ & $63 \%$ \\
Brother & $8 \%$ & $54 \%$ \\
Any member & $32 \%$ & $91 \%$ \\
\hline
\end{tabular}

Table 5.

Source of language learning and level of bilingual fluency: percentages and correlations.

\begin{tabular}{ccccc}
\hline Language source & $\begin{array}{c}\text { Non-fluent } \\
\text { bilingual }\end{array}$ & $\begin{array}{c}\text { Fluent } \\
\text { bilingual }\end{array}$ & \multicolumn{2}{c}{ Fluency } \\
\hline & $(\mathrm{N}=25)$ & $(\mathrm{N}=25)$ & \multicolumn{2}{c}{$(\mathrm{N}=49)$} \\
Parents & $26 \%$ & $\%$ & $\mathrm{r}$ & $p^{\mathrm{a}}$ \\
Grandparents & $20 \%$ & $58 \%$ & 0.44 & 0.002 \\
Other family & $20 \%$ & $58 \%$ & 0.39 & 0.006 \\
School & $80 \%$ & $67 \%$ & -0.15 & 0.304 \\
Traveling & $32 \%$ & $21 \%$ & -0.13 & 0.373 \\
Language classes & $16 \%$ & $13 \%$ & -0.05 & 0.733 \\
\hline
\end{tabular}

Note: ${ }^{\mathrm{a} T w o-t a i l e d .}$ 


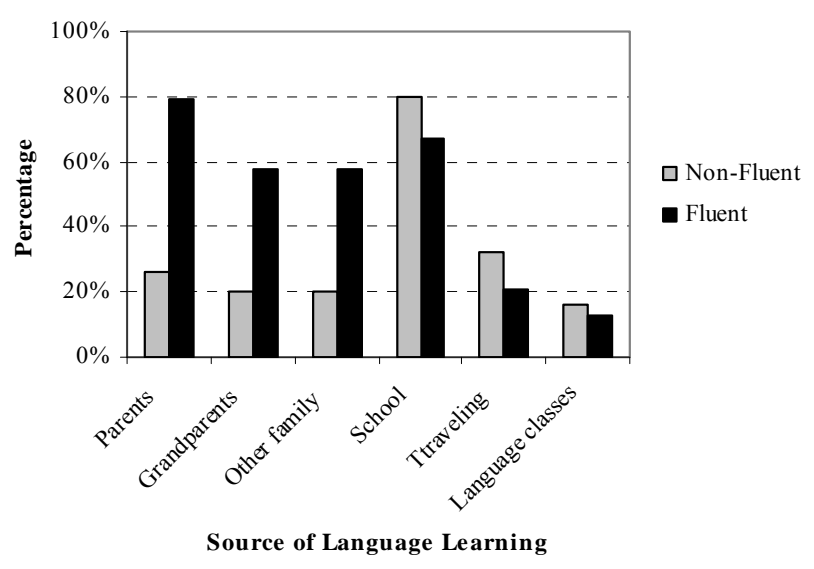

Figure 2.

Source of second language learning for fluent and non-fluent bilinguals.

other family members were the strongest correlates with becoming fluent in a second language. A stepwise linear regression found that the best predictor of second language fluency was whether or not subjects had learned the language from their parents $(\beta=0.44, \mathrm{SE}=0.13, p<0.005)$. The overall model fit was $\mathrm{R}^{2}=0.19$.

\section{Discussion}

This study aimed to examine the concept of bilinguality on a deeper level. It considered not only whether or not participants were bilingual, but among the bilinguals it sought out possible explanations for different levels of second language mastery. Currently there is no unified definition in the literature for bilinguality. Older studies set very stringent criteria and required full mastery of both languages (Bloomfield, 1933). More modern studies, however, tend to be more lax with some even considering people bilingual who have only receptive abilities in their second language and very little productive abilities (Diebold, 1964).

There are very few studies that examine socioeconomic factors as they relate to bilinguality. For example, Morton and Harper (2007) attributed a better performance on the Simon task to children having a higher socioeconomic status (SES). Although the subjects for the current study were chosen purposefully from higher education institutions that collectively draw students from across the SES spectrum, the only SESrelated effect was that fluent bilinguals tended to come from households that earn less than $\$ 100,000$ per year. This is quite a high break point and does not indicate any clear socioeconomic effect.

There were significant results found for the influence of family members on the development of bilinguality. Close to half the bilinguals in this study came from homes where both their parents were also bilingual as opposed to only $6 \%$ of the monolinguals. This effect was even stronger when we compared the two fluent and non-fluent bilingual groups. Fluent bilinguals were much more likely to have bilingual parents as opposed to either non-fluent bilinguals or monolinguals. These results confirmed the main hypothesis for this study and are consistent with previous findings (Yamamoto, 2001; De Houwer, 2007). It is important to note that even within the bilingual group degree of second language fluency was strongly related to the home environment. It is clear that when one or both parents speak a second language the child has a greater chance of being exposed to the second language, especially if parents communicate with each other and other family members in their native language. Accordingly, it seems sensible that more exposure results in higher levels of fluency.

This study found that having more family members speak a different language is associated with a higher degree of bilinguality in the child. Having a bilingual mother was the best predictor of being bilingual, which is consistent with the strong role most mothers play early in a child's life during the most active period for language acquisition. This result is consistent with earlier research that found a strong influence of bilingual mothers (Baker, 2000; Kamada, 1995).

The next most important person in the family who can foster and nurture bilinguality was found to be the sister. This result is again in line with previous findings in this area (Rashid \& Gregory, 1997). Sisters seem to not only be good teachers of a second language but they may be more willing to communicate in the heritage language with their siblings. Bilingual grandparents, on the other hand, while promoting bilinguality, weren't as influential as parents or siblings.

The most important member of the family for distinguishing non-fluent bilinguals from fluent bilinguals was the father. In part, this is likely due to the addition of another bilingual member to the family (beyond the mother), but it is also likely to be due to the particular role most fathers play in the family. Overall, having a bilingual mother increases the chances of a child becoming bilingual in the first place, having a bilingual sister further helps other family members to become bilingual, but ultimately it is the presence of a bilingual father that is likely to lead to the highest levels of second language proficiency.

In our modern society with increasingly larger number of blended families there is a need to examine the role of stepparents in nurturing bilinguality in their children. The current literature in this area has for the most part neglected this increasingly common family type. In this study we did not find a strong effect for the role of step-parents in second language acquisition. This may be because in the survey there were no questions to measure how long the subject may have lived with any step-parent. If the step-parent has not been in the household for long enough or early enough in the life of the child then their linguistic influence would be expected to be quite limited. On the other hand, if a bilingual step-parent has been in the family for many years and still has not been able to influence the child's language then there must be a specific dynamic involved that diminishes the influence of step-parents compared to birth parents. This is a question that should be addressed by future research.

Lastly, this study examined the influence of second language schooling for the two groups of bilingual respondents. Schooling was found to play a more important role in the language acquisition of non-fluent bilinguals compared to the fluent group. For the fluent group the most important factor was found to be other family members, particularly parents. Finally, as bilinguality is a complex topic it can never be attributed to one single factor, in the present study, familial influence. It is understood that community support or other factors not directly addressed in this study could also have an impact on bilinguality.

\section{Conclusion}

In this study we took a closer look at bilinguality, not as a 


\section{HALSTED}

monolithic characteristic of a person, but as a capability in individuals that is mastered to different degrees. Across the spectrum, from monolingual to non-fluent bilingual to fluent bilingual, it is clear that the influence of family is a strong force in the acquisition, maintenance and ultimate mastery of another language. This study contributes to our current understanding of the development of bilinguality; in particular, the role that family influence plays in promoting and preserving bilinguality among American children.

\section{Acknowledgements}

The researcher would like to thank Dr. Marc Halsted for his valuable advice and suggestions with the survey and final draft of the study. Also thanks to Kristine Miller and Jocelyne Morillo for their assistance in collecting data for this study.

\section{REFERENCES}

Azmita, M., \& Hesser, J. (1993). Why children are important agents of cognitive development: A comparison of siblings and peers. Child Development, 64, 430-444. doi: $10.2307 / 1131260$

Baker, C. (1995). A parents' and teachers' guide to bilingualism. London: Arnold.

Baker, C. (2000). A parent and teacher's guide to bilingualism (2nd ed.) (parent and teacher's guide series No. 1). Clevedon: Multilingual Matters.

Bialystok, E. (1986). Children's concept of the word. Journal of Psycholinguistic Research, 15, 13-32. doi:10.1007/BF01067389

Bialystok, E. (1988). Levels of bilingualism and levels of linguistic awareness. Developmental Psychology, 24, 560-567. doi:10.1037/0012-1649.24.4.560

Bialystok, E. (1999). Cognitive complexity and attentional control in the bilingual mind. Child Development, 70, 636-644. doi:10.1111/1467-8624.00046

Bialystok, E., \& Craik, F. I. M. (2010). Cognitive and linguistic processing in the bilingual mind. Psychological Science, 19, 19-23.

Bialystok, E., Craik, F. I. M., \& Ryan J. (2006). Executive control in a modified antisaccade task: Effects of aging and bilingualism. Journal of Experimental Psychology: Learning, Memory, and Cognition, 32, 1341-1354. doi:10.1037/0278-7393.32.6.1341

Bialystok, E., Craik, F. I. M., Klein, R., \& Viswanathan, M. (2004). Bilingualism, aging, and cognitive control: Evidence from the Simon Task. Psychology and Aging, 19, 290-303. doi:10.1037/0882-7974.19.2.290

Bloomfield, L. (1933). Language. New York: Holt.

Clyne, M. (1982). Multilingual Australia. Melbourne: River Seine.

Dale, P., Harlaar, N., Haworth, C., \& Plomin, R. (2010). Two by two: A twin study of second language acquisition. Psychological Science, 21, 635-640. doi:10.1177/0956797610368060

De Houwer, A. (2007). Parental language input patterns and children's bilingual use. Applied Psycholinguistics, 28, 411-424. doi:10.1017/S0142716407070221

Diebold, A. R. (1964). Incipient bilingualism. In D. Hymes (Ed.), Language in culture and society. NY: Harper and Row.

Eisenstein, M. (1980). Childhood bilingualism and adult language learning aptitude. International Review of Applied Psychology, 29, 159-172. doi:10.1111/j.1464-0597.1980.tb00888.x
Farrell, M. (2011). Bilingual competence and students' achievements in physics and mathematics. International Journal of Bilingual Education and Bilingualism, 14, 335-345. doi: $10.1080 / 13670050.2010 .516817$

Gregory, E., \& Williams, A. (2000). City literacies, learning to read across generations and cultures. London: Routledge.

Harding, E., \& Riley P. (1986). The bilingual family: A handbook for parents. Cambridge: Cambridge University Press.

Kamada, L. (1995). Report on bilingual family case studies in Japan: Significant factors affecting bilinguality. Bunkei Ronso, 30, 3 .

Kenner, C. (2000). Home pages: Literacy links for bilingual children. Stoke-on-Trent: Trentham Books.

Keshavarz, M., \& Astaneh, H. (2004). The impact of bilinguality on the learning of English vocabulary as a foreign language. Bilingual Education and Bilingualism, 7, 295-302. doi:10.1080/13670050408667814

Lambert, W. E., \& Taylor, D. M. (1990). Coping with cultural and racial diversity in urban America. New York: Praeger Publishers.

Levy, B. J., McVeigh, N. D., Marful, A., \& Anderson, M. C. (2007). Inhibiting your native language: The role of retrieval-induced forgetting during second-language acquisition. Psychological Science, 18, 29-34. doi:10.1111/j.1467-9280.2007.01844.x

Linck, J., Kroll, J., \& Sunderman, G. (2009). Losing access to the native language while immersed in a second language. Psychological Science, 20, 1507-1515. doi:10.1111/j.1467-9280.2009.02480.x

Manaster, G., Rhodes, C., Marcus, M., \& Chen, J. (1998). The role of birth order in the acculturation of Japanese Americans. Psychologia, $41,155-170$

Miller, J. (1983). Many voices: Bilingualism, culture and education. London and New York: Routledge.

Morton, J. B., \& Harper, S. N. (2007). What did Simon say? Revisiting the bilingual advantage. Developmental Science, 10, 719-726. doi:10.1111/j.1467-7687.2007.00623.x

Obied, V. (2009). How do siblings shape the language environment in bilingual families? International Journal of Bilingual Education and Bilingualism, 12, 705-720. doi:10.1080/13670050802699485

Oller, D. K., \& Eilers, R. E. (2002). Language and literacy in bilingual children. Clevedon, UK: Multilingual Matters.

Rashid, N., \& Gregory, E. (1997). Learning to read, reading to learn: The importance of siblings in the language development of young bilingual children. In E. Gregory (Ed.), One child, many worlds: Early learning in multicultural communities (p. 112). London: David Fulton.

Shin, H. B., \& Kominski, R. A. (2010). Language use in the United States: 2007, American community survey reports, ACS-12. US Census Bureau, Washington DC.

Shin, S. (2005). Developing in two languages: Korean children in America. Clevedon, UK: Multilingual Matters.

Shum, L. (2001). The effect of environmental factors on bilingualism among Chinese and Korean Americans. Applied Linguistics, 1, 1.

Thomas, J. (1988). The role played by metalinguistic awareness in second and third language learning. Journal of Multilingual and Multicultural Development, 9, 235-247. doi: $10.1080 / 01434632.1988 .9994334$

Trask, R. L. (1999). Key concepts in language and linguistics. New York: Routledge.

Yamamoto, M. (2001). Language use in interlingual families: A Japanese-English sociolinguistic study. Clevedon, UK: Multilingual Matters. 


\section{HALSTED}

\section{Appendix}

\section{Bilingual Study Questionnaire (Selected Items)}

1. Do you speak any languages other than English?

2. What is the other (second) language?

3. Did you learn to speak your "second" language BEFORE you learned to speak English?

4. How old were you when you started to learn the "second" (non-English) language?

5. Do you still speak this "second" language?

6. Approximately how many years have you spoken this second language?

7. Do you speak a third language? If so, what is that language?

8. Where did you learn to speak this second language? Check all that apply.

From parents

From grandparents

From other family members

From friends

In school

While traveling

In language classes outside of school

Other

9. Growing up, who else in your family spoke this second language? Check all that apply.

Mother

Father

Grandparents

Brothers/sisters

Cousins

Aunts/uncles

No one else

Other

10. In what situations do you currently use your second language? Check all that apply.

At school

At work

At home

With parents

With friends

With grandparents

With brothers/sisters

With college roommates

When traveling in another country

At language school/class

Other

11. Currently, how much of the time do you use your second language?

12. How much do you like speaking in your second language?

13. How well can you speak your second language?

14. Are you able to READ in your second language?

15. Are you able to WRITE in your second language?

16. How much do you like WRITING in your second language?
17. Do you ever read books or magazines in your second language for pleasure?

18. How much do you like READING in your second language?

19. Do you ever watch TV shows or listen to radio programs in your second language?

20. Do you like the TV programs or radio programs broadcast in your second language?

21. Do you ever listen to music in your second language?

22. Do you like music sung in your second language?

23. Do you feel proud to be able to speak a second language?

24 . Why or why not?

25 . How comfortable are you speaking your second language in public?

26. Why or why not?

27. Has anyone ever made fun of you speaking your second language?

28. Did your parents encourage/require you to learn your second language?

29. Did your parents require you to go to second language classes?

30. Do you plan to continue to learn/improve/maintain your second language skills?

31. Why or why not?

32. Do you ever feel embarrassed to speak your second language in public?

33. Why or why not?

34. Growing up, did you attend any foreign language classes AFTER SCHOOL OR ON WEEKENDS?

35 . How many years did you attend these language classes?

36. How old were you when you stopped attending these classes?

37. Why did you stop attending your second language school/ classes?

38. How many hours of homework did you have in your second language each week?

39. Did you ever have difficulties with the amount of second language homework?

40. What grades did you usually get in your foreign language school/classes?

41. Have you ever visited a non-English speaking country?

42. Please list the non-English speaking country or countries you have visited.

43. Which non-English speaking country have you spent the most time visiting/living in?

44. How many times have you visited this country?

45. Approximately how old were you when you first visited this country?

46. Approximately how old were you when you last visited?

47. Typically, how long did the visits to this country last?

48. Did you speak in the native language of this country while you visited? 